\title{
A ontologia marxista na perspectiva da ser-outra
}

\section{Marxist ontology from the perspective of being-other-woman}

\section{Tábata Berga ${ }_{\oplus}$}

[...] e que não existem estrangeiros. Existem apenas versões de nós mesmos; muitas delas nós não abra-

çamos, e da maioria desejamos nos proteger. A origem dos outros: Seis ensaios sobre racismo e literatura, Toni Morisson, 2016.

Resumo $\mathrm{O}$ ensaio tem como objetivo lançar uma perspectiva feminista às bases epistemológicas da ontologia marxista, situada geneticamente na visão e estrutura de mundo masculina. Para tanto apresentarei um rascunho da categoria que estou nomeando por ser-outra cuja construção proponho em oposição ao sujeito universal, todavia, historicamente situado. O intuito é oferecer um olhar mais plural à abordagem do ser social, recuperando autoras que permanecem marginalizadas pela tradição filosófica. Palavras chaves Ontologia. Ontologia marxista. Ser social. Epistemologias feministas. Ser-outra.

Abstract The essay aims to launch a feminist perspective to the epistemological bases of Marxist ontology, which is genetically situated in the male world view and structure. To this end, I will present a draft of the category that I am naming being-other-woman - a category which I formulate in opposition to the universal subject (however historically situated). The aim is to offer a more plural outlook at the social being, recovering authors who remain marginalized by the philosophical tradition.

Keywords Ontology. Marxist ontology. Social being. Feminist epistemologies. Beingother-woman.

a Tábata Berg é doutora pelo Programa de Pós-Graduação em Sociologia da Universidade Estadual de Campinas IFCH/UNICAMP, pesquisadora pelo Grupo de Pesquisa Mundo do Trabalho e Suas Metamorfoses GPMT-IFCH/UNICAMP e professora pelo Departamento de Ciências Sociais da Universidade Federal de Viçosa DCS/UFV. É mãe do Antônio desde 2016. 


\section{ENTRE-TECENDO SUJEITO E OBJETO}

Neste ensaio proponho lançar alguns questionamentos aos pilares da ontologia marxista do ser social a partir das epistemologias feministas, dando ênfase à sua pluralidade. Tenho como objetivo desenvolvê-los através da visão de mundo e da estrutura de exposição ${ }^{1}$ das pensadoras mulher (es) ${ }^{2}$ que têm, a despeito da ampla reflexão e lutas políticas, permanecido à margem da tradição ontológica. Rascunharei uma apreensão da ser humana em sua constituição através do fazer-se da ser-outra; isto é, daquelas construídas enquanto estrangeiras ao ser-social, outremizadas $^{3}$ enquanto sujeitos produtores e cognoscentes.

O "ser" de forma ampla tem sido objeto de reflexão da Metafísica há pouco menos de dois milênios e meio - se tivermos como limiar Platão. No entanto, ele tem sido objeto quase que exclusivo de pensadores homens; salvaguardadas algumas raras exceções que são tratadas enquanto párias pela própria ontologia enquanto disciplina institucionalizada, tais como Teresa D’Ávila, no século XVI e Simone de Beauvoir, no século XX.

Teresa D'Ávila escreveu no apogeu do Renascimento, em anos intensos do que ficou conhecido como a "Caça às bruxas" - seu Livro da vida de 1562 ficou sob suspeição da Inquisição. Em sua obra, categorias e questões inerentes ao desenvolvimento da modernidade ocidentalizada são elucidadas de modo autêntico e com uma qualidade literária peculiar. Tais como: a ascensão do sujeito transcendental, sua centralidade enquanto sujeito cognoscitivo e moral e, ainda, as relações entre

1 Encontro nas obras Um teto todo seu (1928) e em Três Guinéus (1938), ambas de Virginia Woolf, a inspiração para o par conceitual visão de mundo e estrutura de exposição. A autora demonstra que a forma de escrita e a visão de mundo encontram-se fundamentalmente articuladas e que as experiências concretas, o modo de vida de um determinado grupo social, no caso, das mulheres, impactam a estrutura de exposição. No entanto, Woolf defende uma necessária transposição desse par conceitual para a produção da escrita literária, a ascensão à visão de mundo e estrutura de exposição andrógenas. Essa questão nos levará ao debate intrínseco tanto ao feminismo quanto ao marxismo da crítica imanente e da crítica transcendente, algo que indico aqui, mas não posso avançar. Ressalto, ainda, que estou utilizando o par visão de mundo e estrutura de exposição em um sentido amplo; por visão de mundo estou compreendendo todas as formas cognoscentes de uma determinada forma de ser. Já por estrutura de exposição estou entendo os procedimentos e os métodos como um determinado conhecimento expressa-se, seja de modo explícito, pela linguagem - da produção científica ao catecismo religioso -, seja de modo implícito, em suas formas pré-linguísticas.

2 Estou utilizando como recurso linguístico os parêntesis. Busco, a partir deles, acentuar aquelas características fundamentais que, não obstante constem na própria raiz etimológica dos termos, são epistemologicamente arrancadas de seus sentidos correntes, como ocorre com pro (criação) e re (produção) e com o plural mulher (es). Utilizo, portanto, os parêntesis invertendo sua função linguística usual. Dos primeiros termos, criação e produção são subtraídos, identificando esses processos sociais, cujas mulher (es) são transformadas em portadoras mudas, a processos biológicos e repetitivos e desprovidos de consciência ativa. Já em relação à categoria mulher (es) no plural, é o caráter diverso, a pluralidade mesma que lhe é amputada. Mesmo quando conjugadas no plural, o pensamento (masculino) tende a lhes reservar uma singularidade universal.

3 Ver Morisson, 2019 [2017]. 
alma e corpo, conhecimento, autoconhecimento e ser, entendimento e experiência, entre outras ${ }^{4}$. No entanto, Teresa não se encontra entre os cânones da filosofia; majoritariamente masculinos. Sua obra só esporadicamente é tratada nas grades de filosofia e, quando o é, a interpretação costuma ser atravessada pela sua "especificidade" feminina, nas palavras de Beauvoir: "ela se apresenta diante do macho como ser sexuado: para ele, a fêmea é sexo, logo ela o é absolutamente" (Beauvoir, 2016 [1949] p. 12). Seu pensamento costuma ser interpretado a partir do lugar simbólico de "esposa de Cristo", posição que, embora ela mesma tenha se arrogado ${ }^{5}$, passou a obscurecer suas contribuições filosóficas. Tal imagem foi consagrada pela escultura Êxtase de Santa Teresa, do artista barroco Gian Lourenzo Bernini, no século XVII.

No que tange a ontologia marxista ${ }^{6}$, embora um número crescente de pensadoras esteja oferecendo contribuições riquíssimas7, a tradição ainda encontra-se fundamentalmente ancorada nas obras de Marx e Lukács. Essas duas dimensões basilares do objeto encontram-se transpassadas pela visão de mundo e estrutura de exposição masculinas, e que trazem não somente a exclusividade do olhar masculino ${ }^{8}$, mas também branco e europeu (colonizador e burguês) ${ }^{9}$. Quantas vezes o conhecimento sobre o ser social, assim como aquele produzido a respeito

4 Vejamos o seguinte trecho: "Pois bem! Tornemos agora ao nosso castelo de muitas moradas. Não havei de imaginá-las umas depois das outras, todas enfileiradas. Não! Ponde os olhos no centro: aí é a sala ou o palácio onde está o Rei. Como num palmito, no qual para chegar ao que se come, há muitas cascas ou camadas que cercam inteiramente a medula saborosa, assim aqui, em redor desta sala há muitas outras, e também por cima. Efetivamente, as coisas da alma sempre se hão de considerar com plenitude, amplidão e grandeza. Não há perigo de exagero, pois sua capacidade excede qualquer consideração humana, e o sol, que está no centro do palácio comunica-se a todas as partes" (D’Ávila, 2011 [1577], p. 27). Nele, Teresa D’Ávila discorre sobre a relação entre as partes e o todo que compõem a noção renascentista de indivíduo, e como através da oração reflexiva é possível debruçar-se e conhecer a intimidade dessas partes; sua essência no todo, no sol central.

5 "Logo se representou a mim, como de outras vezes, por visão imaginária, muito interiormente, e, dando-me a mão direita, disse: 'Olha este cravo: é sinal de que será desde hoje minha esposa. [...]”’ (D’Ávila, 2011 [1577], p. 270).

6 Por ontologia marxista estou compreendo a tradição iniciada por György Lukács em Para uma ontologia do ser social (1968), na qual a leitura da obra marxiana é feita a partir da centralidade ontológica da categoria trabalho como aquela de transição entre o ser orgânico (no qual o movimento do ser é um movimento causal e não intencional) e o ser social, forma na qual o ser e suas causalidades internas é posto em movimento pela teleologia do trabalho de desdobrando em pores primários e secundários.

7 Ver, por exemplo, Saffioti, 2001; Arruza, 2016; Ferguson, 2016.

8 Estou utilizando "visão de mundo e estrutura de exposição masculinas" no artigo como uma forma social, uma categoria, no sentido marxiano, hegemônica que ascende com a modernidade capitalista. No entanto, não estou desconsiderando formas de masculinidades dissidentes e não-hegemônicas, uma vez que elas também encontram-se em uma posição subalterna em relação à visão de mundo e estrutura de exposição masculinas, sendo também lançados à condição de ser-outra.

9 Frantz Fanon, nas décadas de 50 e 60, e Achille Mbembe em A crítica da Razão Negra (2014[2013]) demonstram como colonização e escravização estruturam o pensamento ocidental. 
da (s) "mulher (es)", disse tanto sobre a posição ocupada nas relações sociais pelos homens produtores que ofuscou a complexidade do próprio objeto de pesquisa?

Toda construção epistemológica do outro é ontologicamente relacional; de fato, "não se pode falar de homens sem falar de mulheres" (Mies, 1984, p. 165. Tradução própria). Ora, ao falar do homem e do sujeito, a (s) mulher (es) - bem como o povos colonizados -, em suas distintas condições, no mais das vezes, foi concebida pela ontologia, seja ela grega, cristã e, em alguma medida, mesmo a marxista, enquanto objeto do ser e só marginalmente enquanto seus sujeitos. Estando nessa posição, como posso recorrer, portanto, à tradição que carrega meu objeto? Ou, pelo menos, como posso recorrer a essa tradição sem questioná-la? E, questionando-a, será possível mantê-la nos pilares dessa apreensão científica?

Simone de Beauvoir compreende que só é possível apreender o ser mulher em seu ser-outra por meio da análise cuidadosa de seu estar situada, de sua experiência vivida. Ela o faz em diálogo com as noções de situação vivida, de Sartre, e das discussões feitas por Merleau-Ponty a respeito do caráter fundamental da experiência perceptiva à constituição da consciência, do corpo e do processo cognitivo de apreensão do objeto. Segundo Merleau-Ponty:

Só falo de meu corpo em idéia, do universo em idéia, da idéia de espaço e da idéia de tempo. Forma-se assim um pensamento “objetivo" (no sentido de Kierkegaard) - o do senso comum, o da ciência -, que finalmente nos faz perder contato com a experiência perceptiva da qual todavia ele é o resultado e a conseqüência natural. Toda a vida da consciência tende a pôr objetos, já que ela só é consciência, quer dizer, saber de si, enquanto ela mesma se retoma e se recolhe em um objeto identificável. E todavia a posição absoluta de um só objeto é a morte da consciência, já que ela imobiliza toda a experiência, assim como um cristal introduzido em uma solução faz com que ela instantaneamente se cristalize (Merleau-Ponty, 2006 [1945], p. 109).

Nesse sentido, buscando fugir à imobilidade da eternização do arbitrário, à morte da consciênciapela fixação de um objeto que não se reconhece constituindo-se na relação com outros, é preciso lançar luz àqueles objetos, sobretudo àqueles sujeitos objetificados, e, portanto, denegados de uma experiência científica legítima. Ressalto, portanto, que a tradição evocada pelo meu "estar situada" é, antes de tudo, tradição oral, transmitida de mãe e pai para filha na cozinha mineira, entre causos e cuidados, panelas e temperos, cueiros e crias; entre sangue e leite. É bem verdade, até há pouco pude não percebê-la enquanto tradição efetivamente viva 
e determinante; pude me dissolver na inautenticidade do ser abstrato e universal, do homem que trabalha, do habitus enquanto categoria ontológica, dos pores teleológicos que põem novas causalidades em movimento, da práxis revolucionária. Eu pude reivindicar a tradição (masculina)! Não posso mais.

O que mudou? A posição, claramente frágil, que possibilitava a minha ilusão de pertencimento ao "mundo dos homens". Da ciência (marxista) ao gestar, parir e criar. Confinada nos trabalhos femininos compreendidos como não produtivos, aquém, às margens, das luzes da criatividade - lançados aos porões da determinação biológica, do não racional. Re (produção) sem criação! Afinal, assim como no livro do Gênesis, a criação - ativa e produtiva - coube/cabe ao deus homem. À mulher: a escolha entre ser "auxiliar semelhante do homem" ou aceitar a punição da pro (criação) sob o patriarcado: "Javé Deus disse então para a mulher: Vou fazê-la sofrer muito em sua gravidez: entre dores você dará à luz seus filhos, a paixão vai arrastar você para o marido, e ela a dominará" (Genesis, 3,16 ).

Parece-me equivocada a identificação entre o conhecimento, cujo fruto proibido deu acesso, à racionalidade pura, contemplativa, iluminista - masculina, branca e burguesa. Esta sempre reinou no paraíso. A sabedoria do fruto é de outra ordem: é conhecimento mediatizado pela materialidade da experiência vivida, pelos sentidos, pelo estômago "uma árvore apetitosa para dar sabedoria" (Genesis, 3,6), com Eva expulsa do paraíso e posta diante da urgência da vida, condenada a sentir as dores do parto e cultivar a terra da qual se veio. A sabedoria (não o conhecimento puro do deus Homem, a mesma do sujeito universal que, depondo-o, toma o seu lugar no Éden), na mitologia cristã, nasce, contraditoriamente, dos sentidos, emaranhada ao trabalho reprodutivo, ao trabalho manual, nasce da perspicácia desobediente da primeira mulher. A sabedoria é feminina!

Sobre a interpretação masculina do mito cristão de Adão e Eva, a filósofa Mary Wollstonecraft, em 1972, conclui:

[...] todavia, como se supõe que muito poucos dos que pensaram sobre o tema sempre presumiram que Eva era, literalmente, uma das costelas de Adão, tal dedução deve ser esquecida ou admitida apenas como prova de que o homem, desde a mais remota Antiguidade, acho-a conveniente para exercer sua força, a fim de subjugar sua companheira, e utilizou sua invenção para mostrar que a mulher deveria ter seu pescoço sob jugo, porque toda a criação foi feita apenas para a conveniência e prazer do homem (Wollstonecraft, 2016 [1792], p. 47). 
A conveniente e seletiva interpretação masculina serviu (e assim segue, bem menos explícita no mundo das luzes) para manter-nos despojadas da racionalidade plena; na prática, denuncia a autora: a pretensa inferioridade feminina deduzida a partir da teologia cristã (da biologia, filosofia, psicologia, entre outras esferas do conhecimento) nos manteve afastadas do acesso à educação formal, concebendo-nos como seres perpetuamente infantis, como rascunhos inacabados da potencialidade humana. E quando, enfrentando muitas dificuldades, as mulheres acessaram o conhecimento formal, exercendo-o ativamente, foram simplesmente apagadas da história da tradição.

Mary Wollstonecraft, a despeito de ter sido filósofa iluminista proeminente nos círculos intelectuais e literários franceses e ingleses ${ }^{10}$, pioneira em perceber e questionar, através da filosofia política iluminista, a exclusão das mulheres da pretensa universalidade intrínseca aos direitos do homem, permanece sendo ignorada, e, quando é recuperada, deve-se ao seu vanguardismo feminista e à sua militância abolicionista: sua contribuição à filosofia iluminista segue na obscuridade $^{11}$. Em sua obra Reinvindicação dos direitos da mulher, de 1792, supracitada, Wollstonecraft estabelece um debate vigoroso, entre outros, com J. J. Rousseau, desmistificando sua construção sobre as mulheres, que termina por comprometer sua filosofia universalista. Enquanto Rousseau, com toda a debilidade apontada pela autora a respeito do lugar que confere à condição humana das mulheres, é cânone da tradição filosófica.

A (s) mulher (es), sua história e sua filosofia - metade da humanidade -, quando digna de nota, permanece sendo concebida enquanto particularidade.

Nesse sentido, ser lançada aos porões do cuidado, enclausurada na marginalidade da nominada esfera re (produtiva), foi, para além da punição, um abrir de olhos, um sentir-me nua: possibilidade de acessar um conhecimento mediatizado. A escritora estadunidense Bell Hooks, na década de 80, defende que a posição marginal conduz, ao risco da sobrevivência, o marginalizado à apreensão da totalidade, em suas palavras:

10 Mary Wollstonecraft foi literata, filósofa e ativista reconhecida em seu tempo histórico. Em 1790 ela escreve o panfleto Vindication of the rights of men em reposta a Edmundo Burke, antes de Reivindicação dos direitos da mulher (1792), texto que foi amplamente lido e debatido na época. O mesmo aconteceu com Reivindicação dos direitos da mulher, tendo esgotado quase imediatamente, e recebido uma segunda edição na Inglaterra, teve várias edições norte-americanas, e foi traduzido para o Francês.

11 E. P. Thompson aponta em Wollstonecraft (1974) essa contradição inerente à condição das mulher (es) intelectuais que a despeito de suas reflexões públicas [e publicadas], suas vidas íntimas e posições pessoais são mobilizadas tanto para invisibilizar quanto para descredibilizar as primeiras Thompson, 2000 [1974]. 
E por viver como vivíamos - nas extremidades - desenvolvemos um modo particular de enxergar as coisas. Olhávamos tanto de fora para dentro quanto de dentro para fora. Focávamos nossa atenção no centro assim como na margem. Compreendíamos ambos. Essa forma de ver nos lembra da existência de todo um universo, um corpo principal com sua margem e seu centro. Nossa sobrevivência depende de uma conscientização pública contínua da separação entre margem e centro e de um contínuo reconhecimento privado de que nós somos uma parte necessária. Vital, desse todo.

Esse senso de inteireza, gravado em nossas consciências pela estrutura de nossas vidas cotidianas, haveria de nos prover de uma visão de mundo contestadora [...] (Hooks, 2019 [1984], p. 23).

Para o "jovem” Lukács (1922) o que distingue a burguesia do proletariado é que, enquanto a primeira só pode acessar parcialmente o real, e, ainda assim, de modo contemplativo, o segundo pode apreendê-la em sua totalidade por meio das categorias de mediação. Isto é, a distinção, no que tange a apreensão do real, entre burguesia e proletariado é a "diversidade da situação [verschiedenen Lage] das duas classes no "mesmo" processo econômico" (Lukács, p. 310, 2003 [1922]). O conhecimento é, portanto, acessado através da mediação da consciência posicionada nas cadeias radicais do processo histórico. A mediação - categoria, no "jovem" Lukács, abstrata, e por vezes, contemplativa - encontra em hooks a materialidade no movimento dialético de "cruzar trilhos da estrada de ferro" que separam centro/ periferia, mundo branco/mundo negro, capital/trabalho.

De tal modo que provar do fruto proibido foi ser atirada ao centro das cadeias radicais do patriarcado, e, ao mesmo tempo, mantida às margens da razão, da produção, da verdadeira criação. Daí, questionar os fundamentos sob os quais se desenvolve minha pesquisa, radicalizar "os fundamentos históricos da razão"12 se tornou para mim tarefa imprescindível.

É importante ressaltar que tal proposta lançada por esse ensaio tem sido vastamente empreendida por pensadoras em diversas correntes do pensamento social e filosófico, com reflexões plurais, divergentes e riquíssimas; várias delas fomento para o movimento que aqui rascunho. Os trabalhos da brasileira Lélia Gonzalez (décadas de 80 e 90), da belga Luce Irigaray (entre os anos 1970 e 2000) e da estadunidense Judith Butler (a partir da década de 90) são expressivos dessa diversidade. As três filósofas, em intenso diálogo com a psicanálise e a linguística,

12 Ver Bourdieu, 1997/2007, p. 113. 
empenharam-se, cada qual a seu modo, na desconstrução do sujeito universal e metafísico.

Lélia Gonzalez desconstrói a universalidade do sujeito branco e universal, em cuja soberania se constrói o racismo por denegação que marca as colonizações ibéricas, propondo a construção da categoria amefricanidade. Para ela, há uma diáspora comum que conecta as distintas experiências amefricanas, que possibilita unificar, frente ao imperialismo, as experiências do racismo declarado, por exemplo, estadunidense, e do racismo por denegação, como é o caso brasileiro. Uma diáspora que se integra à totalidade da africana, mas lhe é peculiar, ao ser reinventada sob o perverso processo de escravização dos povos negros e indígenas, isso porque a escravidão foi a instituição fundamental e fundante sobre a qual se ergueram as relações sociais no continente amefricano ${ }^{13}$. Segundo Gonzalez em A categoria político-cultural de amefricanidade (1988):

Portanto, Améfrica, enquanto sistema etnogeográfico de referência, é uma criação nossa e de nossos antepassados no continente em que vivemos, inspirados em modelos africanos. Por conseguinte, o termo amefricanas/amefricanos designa toda uma descendência: não só a dos africanos trazidos pelo tráfico negreiro, como daqueles que chegaram à AMÉRICA muito antes de Colombo. Ontem como hoje, amefricanos oriundos dos mais diferentes países têm desempenhado um papel crucial na elaboração dessa Amefricanidade que identifica, na Diáspora, uma experiência histórica comum que exige ser devidamente conhecida e cuidadosamente pesquisada. Embora pertençamos a diferentes sociedades do continente, sabemos que o sistema de dominação é o mesmo em todas elas, ou seja: o racismo [...] (Gonzalez, 1988a, p. 77).

Essa peculiaridade da experiência amefricana que, segundo Gonzalez, estrutura o conjunto das relações societais - materiais e simbólicas - na Améfrica Ladina, é um aspecto muito profícuo à categoria que estou desenvolvendo, pois, a autora acentua modos de ser-outras que, embora geneticamente ligados à diáspora africana, são-lhe distintos ${ }^{14}$.

Por serem plurais, das diásporas coloniais/imperiais também se desdobram perspectivas analíticas particulares, por exemplo, daquelas que nasceram nas

13 Segundo Abdias Nascimento: "No Brasil, é a escravidão que define a qualidade, a extensão e a intensidade da relação física e espiritual dos filhos de três continentes que lá se encontraram [...]" (Nascimento, 2016 [1976], p. 57).

14 Nesse caso, amefricanidade que é ladina, astuta (Métis). 
metrópoles ou para lá migraram vindas da África, Améfrica, Ásia e Índia, como é o caso de Avtar Brah, Grada Kilomba, Hazel Carby (1996), entre outras. Avtar Brah, por exemplo, explicita a distinção entre a configuração político-teórica da categoria negro na Grã-Bretanha em relação à estadunidense:

Como os processos culturais são dinâmicos, e o processo de reivindicação é também mediado, o termo "negro" não precisa ser construído em termos essencialistas. Pode ter diferentes significados políticos e culturais em contextos diferentes. Não se pode considerar que seu significado específico na Grã-Bretanha do pós-guerra tenha negado diferenças culturais entre povos africanos, caribenhos e sul-asiáticos quando a diferença cultural não era o princípio organizador dentro desse discurso ou prática política. As lutas políticas concretas em que o novo significado se fundava reconhecia diferenças culturais, mas buscava realizar a unidade política contra o racismo (Brah, 2006 [1996], p. 335).

Lélia Gonzalez, em Por um feminismo Afro-latino-americano (1988), consonante com diversas outras teóricas do feminismo negro, demonstra o quanto uma definição de sujeito feminino, ao manter-se ancorada em uma concepção que universaliza a mulher branca das metrópoles, reproduzindo um arquétipo de mulher, por conseguinte, de feminismo abstrato e excludente, reifica justamente uma lógica a-histórica cuja pretensão foi romper, desdobrando-se na exclusão de todas aquelas que terminam por não compartilhar dessas experiências que, colocando-se como universais, são, sobretudo, particulares. Vejamos:

[...] nós mulheres e não-brancas fomos "faladas", definidas e classificadas por um sistema ideológico de dominação que nos infantiliza. Ao impormos um lugar inferior no interior da sua hierarquia (apoiadas nas nossas condições biológicas de sexo e raça), suprime nossa humanidade justamente porque nos nega o direito de ser sujeitos não só do nosso próprio discurso, senão da nossa própria história. É desnecessário dizer que com todas essas características, nos estamos referindo ao sistema patriarcal-racista (Gonzalez, 1988b, p. 14. Grifos meus).

Já Irigaray se empenha em compreender a alteridade feminina, não enquanto alteridade absoluta, em contraposição ao sujeito masculino, tal como foi empreendido por Simone de Beauvoir, mas como outra construída com autonomia e linguagem próprias. Em uma revisão de seus trabalhos anteriores, a autora afirma: 
Colocar o dois em lugar do um na diferença sexual significa, portanto, um gesto filosófico e político decisivo, aquele que renuncia a ser um no plural para passar a ser dois, como fundamento necessário de uma nova ontologia, de uma nova ética, de uma nova política, na qual o outro é reconhecido como outro e não como um mesmo: maior, menor, no melhor dos casos, igual a mim (Irigaray, 2002, p. 12 ).

Ao conferir conteúdo particular ao feminino, compreendendo-o enquanto diferença capaz de constituir-se de modo autônomo, e não como um reflexo distorcido e amputado de um Sujeito cuja imagem devemos perseguir, a autora questiona o cerne da estrutura do método de conhecimento ocidental para que o outro - em sua diversidade de condições e posições - longe de ser concebido e, consequentemente, conhecido a partir de suas características intrínsecas, é, antes, e no mais das vezes exclusivamente, percebido como uma imagem inacabada e/ ou deformada desse Sujeito uno e universal'15: "como o sujeito filosófico, historicamente masculino, reduziu o outro em uma relação com ele - complemento, projeção, inverso, instrumento, natureza... - no interior de seu mundo, de seu horizonte". [...] (Irigaray, 2002, p. 2).

A autora defende que uma compreensão do masculino e do feminino, enquanto subjetividades autônomas, distintas e irredutíveis uma à outra, abriria possibilidades de reconhecimento de tantas formas de diferenças que também são relegadas à condição de inferioridade. As mulheres, no entanto, parecem percebidas por Irigaray a partir de categorias universais. Ao propor o dois em detrimento do modelo único, esse dois, embora não binário - por não construir-se de modo relacional e em dependência ao outro - é universalizado: "trato das particularidades do mundo feminino, mundo diferente daquele do homem, em sua relação com a linguagem, com o corpo (idade, saúde, beleza e claro, a maternidade), em sua relação com o trabalho, a natureza e o mundo da cultura" (Irigaray, 2002, p. 6. Grifos meus).

Judith Butler, por sua vez - e tendo estabelecido um longo diálogo com Irigaray -, renuncia à categoria de mulheres enquanto sujeito estável, unitário e

15 Achille Mbembe demonstra que a Razão negra, construção epistemológico ocidental sobre a raça, também se estrutura sobre a concepção do sujeito uno e universal que se opõe à construção do sujeito racial "Tentando responder a questão "Quem é esse?” (sujeito racial), ele (primeiro conjunto de elaborações que articulam ciência e ficção) se esforça por nomear uma realidade que lhe é exterior e que ele tende a situar em relação a um eu tomado como centro de toda e qualquer significação. A partir dessa posição, tudo o que não é idêntico a si é anormal " (op. cit, pp. 61 e 62, acréscimo de explicações entre parêntesis). 
previamente construído em relação às formas concretas de organização feminista ${ }^{16}$, seja em sua forma filosófica ou política. Rompendo não apenas com uma ancoragem de sexualidade e gênero no sexo biológico mas com a própria existência a priori do sexo biológico, a autora não somente se empenha em questionar e desconstruir o sujeito universal, como também questiona a pretensa universalidade da categoria mulheres como sujeito político. Em debate com Seyla Benhabib e Nancy Fraser em 1990, defende:

Eu argumentaria que qualquer tentativa de dar conteúdo universal ou específico à categoria das mulheres, presumindo que a garantia da solidariedade seja exigida previamente, irá necessariamente produzir facciosidade, e que "identidade" como ponto de partida não se sustenta como base segura para um movimento político feminista (Butler, 2018 [1995], p. 85).

Ela questiona que a ação dentro do movimento feminista baseado na unidade, nomeadamente em uma certa unidade da categoria mulheres, mesmo que ampliada, forjaria uma relação dialógica que, por um lado obscurece as diferenças, por outro as cristaliza em uma concepção linear de "identidades”, podendo mesmo cair em um posicionamento liberal para a qual a igualdade pressuposta entre as diversas "identidades" se põe como possibilidade do diálogo e, consequentemente, da ação política. Butler propõe pensar em coalizões em contraposição à unidade: “Talvez as coalizões devam reconhecer suas contradições e agir deixando essas contradições intactas" (Butler, 2003 [1990], p. 41)

Em um sentido similar, a poeta norte-americana Audre Lorde (1984), embora reivindicando a noção de unidade, se opõe radicalmente à diluição das diferenças nas diversas frentes de luta contra as opressões:

Para trabalharmos juntos, não é preciso que nos tornemos uma mistura de partículas indistintas que se assemelham há um barril de leite achocolatado homogeneizado. Unidade implica a reunião de elementos que são, para começar, variados e diversos em suas naturezas individuais. Nossa persistência em examinar as

16 Sobre Irigaray, Butler questiona: "Na verdade, o texto de Irigaray é frequentemente obscuro sobre a questão de saber se a sexualidade é culturalmente construída, ou se é só culturalmente construída nos termos do falo. Em outras palavras, estaria o prazer especificamente feminino "fora" da cultura, como sua pré-história ou seu futuro utópico? Se assim for, de que serve essa noção nas negociações das disputas contemporâneas sobre a sexualidade em termos de sua construção?” (Butler, 2003 [1990], p. 64). 
tensões intrínsecas à diversidade estimula o crescimento em direção ao nosso objetivo comum (Lorde, 2019 [1984], p. 172).

Entretanto, a despeito da enorme diferença entre as três autoras (e entre as demais autoras que serão mobilizadas neste ensaio) e das divergências que esse ensaio apresenta em relação aos seus constructos, elas trazem críticas radicais aos fundamentos, isto é, ao sistema ontológico/epistemológico sobre o qual a noção de sujeito se erigiu, que, na busca por contribuir com uma apreensão ontológica do ser social, são pontos de partida para o desenvolvimento da categoria ser-outra.

Compreender as imbricações entre formas distintas de opressão e exploração que levam a uma experiência particular do ser-mulher (es), assim como atentar para uma desvinculação radical entre gênero e sexo biológico e sexualidade que desdobra-se em desconstrução, não somente do sujeito universal masculino mas também da própria concepção de outro que lhe é necessariamente inerente, traz um questionamento imprescindível dos fundamentos masculinos, brancos, colonizadores, burgueses, heterossexuais que pautam a concepção mesma da relação sujeito/outro. Sendo ser-outra uma categoria que busco desenvolver dentro da perspectiva ontológica marxista, as reflexões dessas autoras, cada uma ao seu modo (e também de Audre Lorde, Toni Morisson, Joan Scott, Avtar Brah, Grada Kilomba, Achille Mbembe, entre outras), ressaltam que epistemologia (s), assim como as categorias de pensamento que lhe (s) estrutura (m), estão sempre enraizadas em formas de ser. Ao me referir às formas de ser estou partindo da ontologia marxista de György Lukács (1968).

Lukács desenvolve a noção de uma ontologia do ser social, de uma ontologia marxista. Ontologia - que, na história do pensamento filosófico e social, tem abordagens bem diferenciadas, algumas ancoradas na metafísica -, do ponto de vista do materialismo marxista, é percebida como o estudo dos desdobramentos reais e objetivos do ser, dos quais a especificidade do ser social é o momento privilegiado.

Sendo assim, ao pressupor uma ontologia marxista e feminista do ser social, busco compreendê-la em sua processualidade concreta: enquanto o fazer-se humana. Fazer-se que é processo ativo e histórico e que só pode ser, em alguma medida, apreendido indo além das "entificações", isto é, do o que é percebido em sua imediaticidade: através da relação dialética entre formas e conteúdos. Entre conteúdos permanentes e transitórios da sociabilidade humana, todavia, sempre modificados por suas formas sociais determinadas.

O diálogo com essas autoras me ajuda a demonstrar que, mesmo sob a égide do capital, forma de ser e epistemologia são plurais, pois se a relação capital/ 
trabalho assalariado tem por necessidade se universalizar, essa universalidade só é possível na transformação de alteridades em ser-outras, ao mesmo tempo em que os movimentos de resistência frente o avanço do capital cria obstáculos a essa universalização, a ser-outra se torna, assim, sujeito subalterno ativo. Buscarei mostrar a seguir alguns desses elementos.

\section{SER-OUTRA: UM BREVE RASCUNHO}

Simone de Beauvoir (1949) elabora sua concepção de Outro absoluto, no qual a mulher estaria encerrada e sobre cujos fundamentos a categoria ser-outra está sendo construída. Ela o faz no âmago do existencialismo e baseando-se na dialética do senhor e escravo de Hegel, nas teorias etnográficas, especialmente de Lévi-Strauss, e na situação e formação materiais e simbólicas do tornar-se mulher.

Segundo a autora, há no sujeito a necessidade original de alienar-se em outro, de exteriorizar-se, de fazer-se (no) objeto. Sendo assim, possuir o objeto que resultou de sua alienação é um ato de retomada de si, é uma forma de interiorização ativa: "[...] o existente só se apreende alienando-se, ele se procura através do mundo sob uma forma exterior e que faz sua. No totem, no mana, no território que ocupa é sua existência alienada que o clã encontra [...] (Beauvoir, 2016 [1949], p. 87).

Em processo análogo, o Outro (sujeito) que surge à consciência do sujeito enquanto objeto, sob o "impulso original" de concebê-lo como exteriorização de si, também constrói enquanto Outro aquele diante de si; busca objetivá-lo. Nesse confronto - que é sempre um processo simultâneo de exteriorização e interiorização -, seja amistoso ou hostil entre dois sujeitos individuais ou coletivos, estabelecem-se formas distintas (complementares ou hierarquizadas) de reconhecimento mútuo, isto é, subjetividades interiorizadas, mas, ao mesmo tempo, partilhadas: intersubjetivas. A mulher, em seu fazer-se, contudo, reforça Simone, não é Outro reconhecido; é, sobretudo, alteridade absoluta.

Difiro-me de Beauvoir, para a qual há uma constituição histórica da superioridade do homem sobre a mulher que se ancora, mesmo que parcialmente, na desvantagem biológica feminina de concentrar em si, indissoluvelmente em suas entranhas, parte do processo re (produtivo) - embora com conformações distintas, e tendo na superação o horizonte epistemológico e ético -; cuja hegemonia foi alcançada pela ascensão da propriedade privada: "Assim o advento do patriarcado não foi nem um acaso nem uma revolução violenta. Desde a origem da humanidade, o privilégio biológico permitiu aos homens afirmarem-se sozinhos como sujeitos soberanos" (Beauvoir, 2016 [1949], p. 112). 
A antropologia e a historiografia, em particular, feministas têm nos fornecido dados importantes para questionar a pretensa constância histórica dessa superioridade. Tal como apontou os estudos de Margaret Mead (1935) sobre a conformação de temperamentos sexuais peculiares: suas pesquisas etnográficas não identificaram nas tribos Arapesh e os Mundugumor a presença de uma diferenciação binária de temperamentos que condicione a superioridade e a dominação de um sexo sobre outro.

Enquanto que para os Tchambuli há uma inversão das personalidades masculinas e femininas, se tomarmos as divisões entre os sexos na sociedade ocidental como referencial: "observamos a verdadeira inversão, entre os Tchambuli, da posição de dominância dos dois sexos, a despeito da existência de instituições patrilineares formais" (Mead, 2014 [1935], p. 268).

Mead demonstra que atividade e passividade - ou imanência e transcendência, para Beauvoir - que na nossa sociedade ocidental foram atribuídas, respectivamente, ao masculino e ao feminino são variações do temperamento humano geral que, combinadas de acordo com a peculiaridade da organização social, condicionam ou não uma distinção de temperamentos sexuais. Assim, a própria binaridade dos temperamentos sexuais ancorada na distinção do sexo biológico é uma combinação social. Sendo a natureza humana, segundo a autora, incrivelmente maleável, as determinações biológicas do sexo não podem, portando, explicá-la.

Sexo e Temperamento é uma obra pioneira. Tendo sido publicada quatorze anos antes de Segundo Sexo traz um prelúdio poderoso, em especial, por ancorar-se na observação de práticas societais concretas, de questões que serão radicalizadas no campo teórico, por exemplo, por reflexões de Joan Scott, Monique Wittig, Judith Butler, entre outras. E, ao optar pelas terminologias mulher (es) e patriarcado, não me oponho à compreensão de que de que sexo e gênero ${ }^{17}$ não possuem uma vinculação necessária; de que o próprio binarismo sexual é uma construção histórica, limitada e limitante, se pensarmos as muitas outras possibilidades de configuração das relações de gênero, em suma, de que o sexo mesmo enquanto categoria, longe de possuir uma objetividade e determinação que lhe é própria, inerente à esfera biológica, é, sobretudo, um constructo social arbitrário. De fato, endosso essas indagações como possibilidades inerentes e horizontes emancipatórios à condição da ser-humana.

17 Definição de gênero, segundo Scott: “O núcleo essencial da definição baseia-se na conexão integral entre duas proposições: o gênero é um elemento constitutivo das relações sociais baseado nas diferenças percebidas entre os sexos, e o gênero é uma forma primeira de significar as relações de poder" (Scott, 2019 [1990], p. 21). 
Vale lembrar que Mary Wollstonecraft já em 1792 questionava o que hoje parte da teoria contemporânea feminista define por identidade de gênero como algo natural e intrínseco ao sexo biológico; em seu já citado debate com Rousseau ela se posiciona radicalmente contrária à cristalização de duas características tidas como fundamentalmente femininas, e que encontraram ao longo da história (masculina) do pensamento novas configurações pseudocientíficas.

Em seu embate com o pensamento iluminista (masculino), a autora tanto nos oferece subsídios para questionar a essencialização do particular quanto a adesão à universalidade abstrata, ambos fundamentos da modernidade. Para tanto debruça-se sobre as condições históricas reais das mulheres das classes médias europeias de seu tempo, historicizando a pretensa particularidade a-histórica que as mantém enquanto apátridas do lócus da racionalidade; concebendo-as enquanto seres perpetuamente infantis e frágeis: reféns do coquetismo e de uma sensibilidade sensual. Ao mesmo tempo em que questiona uma universalidade abstrata que segue marginalizando pelo menos metade da humanidade; ao impedir as mulheres de acessar os pressupostos fundamentais para o exercício efetivo da racionalidade, como educação formal e exercícios físicos que possibilitem o desenvolvimento saudável de mentes e corpos femininos.

Quando Scott defende que homens e mulheres são categorias vazias e transbordantes (Scott, 2019 [1990], p. 28), o que em muito se aproxima tanto de Mary Wollstonecraft quanto de Margaret Mead, essa é uma orientação que perpassará o desenvolvimento da categoria ser-outra. No sentido que a identidade desta categoria com a de mulher (es) é condicionada por uma forma socialmente determinada; mulheres é um conceito que, sem a concretude da história, é vazio, podendo mesmo, como sugere Butler, ser suprimido. O conteúdo histórico da categoria sobre a qual me debruço é, ademais, múltiplo e transborda e mesmo inviabiliza uma compreensão universal de ser-mulher (es).

Também compartilho da conclusão à qual Beauvoir chega de que o patriarcado, como forma de opressão e exploração dos homens sobre as mulher (es), encontra-se geneticamente relacionado ao surgimento da propriedade privada. Mas, ao falar de ser-outra, estou compreendendo-a ancorada na propriedade privada em sua forma singular, a propriedade capitalista, isto é, enquanto forma que ganha contorno e substância particulares no processo de acumulação de capital. Portanto, ao tomá-la enquanto categoria explicativa fundamental, o faço partindo do patriarcado tal como ele se estrutura nesse modo de produção. Embora não se possa deixar de refletir a respeito dos entroncamentos, a partir das permanências e reestruturações, entre o patriarcado em sua forma capitalista e as formas deste nas sociedades 
que foram e seguem sendo invadidas e saqueadas e exploradas pelo capital. Essas imbricações fazem com que a ser-outra seja constituída e experimentada numa multiplicidade de formas.

Lorena Cabnal, intelectual indígena, representante do feminismo comunitário ${ }^{18}$, denominou por patriarcado original ${ }^{19}$ a estrutura que ordena relações de hierarquização, exploração e opressão das mulheres, bem como das representações femininas, nas sociedades originárias na Abya Yala²0: "existe patriarcado originário ancestral, que é um sistema milenar estrutural de opressão contra as mulheres originárias ou indígenas" (Cabnal, 2010, p. 14. Tradução própria).

Cabnal, ao se opor a uma cosmologia binária, masculina e heteronormativa, questiona e rivaliza com a essencialização das epistemologias indígenas, lembrando-nos que essa epistemologia, assim como qualquer meta-conhecimento, é sempre processual e histórica e, portanto, mutável, sendo transpassada pelas relações sociais nas quais encontra-se inserida. Ao mesmo tempo em que denuncia a perniciosidade de uma estrutura, mesmo originária, que hierarquiza e oprime e normatiza a partir da binaridade sexual homens, mulheres e crianças. A autora propõe a construção de uma epistemologia feminista indígena que se re (aproprie) ativamente dos conhecimentos ancestrais que seguem sendo expropriados pelo sistema capitalista, podendo lançar-lhes suspeitas, "sospechar, y sospechar, $y$ sospechar", questionando e transformando-os à luz da ancestralidade feminina subalternizada ao longo do desenvolvimento dessas sociedades.

Refletir sobre as especificidades que o patriarcado sob a égide da acumulação de capital adquire ao se reestruturar, metamorfoseando, através das diversas

18 O feminismo comunitário procura articular tanto as singularidades das explorações e opressões impostas às mulher (es) indígenas, quanto resgatar seu feminismo ancestral. É um movimento de mulher (es) majoritariamente indígenas da América Latina, tendo se iniciado na Bolívia por volta do início dos anos 2000.

19 É importante destacar que a categoria patriarcado originário remete a uma formação social determinada, portanto, diz respeito a relações sociais específicas e não atemporais. O termo originário dentro da sociologia e antropologia tem remetido sobretudo a uma pré-história universal, ou a povos em estágios "inferiores" da evolução societal; o sentido conferido por Cabnal é bastante distinto. Ela fala dos povos que são originários da América Latina e foram expropriados. De tal modo que patriarcado originário não é um universal abstrato, um estágio anterior e inerente a todos os povos e sociedades, mas uma sistema de opressão e exploração das mulher (es) inerente às cosmologias indígenas. Há, todavia, uma certa pretensão da autora de universalização dentre as experiências ancestrais dessa categoria. Mas vale ressaltar que só no Brasil, segundo o senso do IBGE de 2010, por exemplo, há 305 etnias diferentes, com 274 línguas; com relações sociais e cosmologias singulares.

20 Cabnal propõe compreender a experiência americana, a Améfrica, como uma totalidade constituída a partir dos processos de exploração e opressão e resistência, dando ênfase ao processo de expropriação imposto pela colonização aos povos indígenas. A autora define Abya Yala: "Palabra en idioma del Pueblo Kuna de Panamá que nombra la territorialidad del continente americano, la cual ha sido tomada por diferentes pueblos articulados en el movimento de nacionalidades y pueblos indígenas, en la Cumbres Continentales" (Cabnal, 2010 nota 1, p. 11). 
formas que assume nas sociedades cuja expropriação foi imposta é fundamental para o desenvolvimento da categoria ser-outra rascunhada neste ensaio; pois, embora eu esteja me debruçando sobre sua construção no modo de produção capitalista, esse processo de alterização não pode prescindir da diversidade, sua incorporação subalterna é condição mesma de possibilidade da submissão imposta à ser-outra.

A minha principal inspiração para a compreensão da acumulação capitalista é a releitura de $O$ capital de Marx feita por Rosa Luxemburgo. É dela que extraio essa ideia central sob a qual se desenvolve a categoria ser-outra: o capital necessita ao custo de extinguir-se de um outro diferente ontologicamente, na forma de ser, de si mesmo; tanto para expropriá-lo, quanto para realizar-se e, somente assim, ampliar-se "De uma ou de outra forma, enquanto processo histórico, a acumulação de capital depende, sob todos os seus aspectos, das camadas e sociedades não-capitalistas" (Luxemburgo, 1985 [1912], p. 251). E, embora Rosa tenha em pouquíssimos momentos se debruçado sobre a condição feminina, é luxemburguista a noção de ser-outra como protoforma indispensável e insuperável - dento - do processo de expropriação capitalista. Logo, as reflexões feitas por Cabnal são pistas preciosas a uma compreensão da ser-outra sob o patriarcado branco e capitalista que não se perca numa categorização monolítica (Cabnal, 2010).

Ressalto que a identificação da ser-outra à alteridade absoluta é formal. Isso pois, enquanto sujeito submetida pela opressão e exploração ao não reconhecimento de sua alteridade, nosso fazer-se é, tal como pretendo demonstrar, um processo ativo, mesmo na subalternidade. Em outras palavras: se a alteridade absoluta é o horizonte necessário à acumulação do capital; ele, contudo, enfrenta as mais diversas formas de resistências.

Nessa formação histórica particular, a (s) mulher(res) é concebida enquanto objeto do sujeito universal (não Objekt, objeto natural, matéria-prima, ou de pura contemplação, mas Gegenstand no sentido marxiano ${ }^{21}$, ou seja, um objeto que é transpassado pela ação do sujeito; exteriorização e efetivação do $E u$ consciente e ativo, e mais, um objeto mágico). Virginia Woolf oferece uma apetitosa pista - aos modos do fruto proibido - sobre a natureza desse objeto:

As mulheres têm servido há séculos como espelhos, com poderes mágicos e deliciosos de refletir a figura do homem com o dobro do tamanho natural. Sem esse poder, provavelmente a terra ainda seria pântanos e selvas. As glórias de

21 Ver MARX, 2007 [1845], Tese ad Feuerbach. 
todas as nossas guerras seriam desconhecidas. [...] Seja qual for seu uso nas sociedades civilizadas, os espelhos são essenciais para todas as ações violentas e heroicas (Woolf, 2014 [1929], pp. 54-5).

Metaforizamos espelhos! Representação do surgimento do indivíduo que contrapondo-se e diferenciando-se da coletividade se faz autônomo, ativo. Ao mesmo tempo símbolo da expropriação colonial. Espelho, uma alegoria que condensa a questão da ser-outra: objeto que confere poder, refletindo o indivíduo autônomo, capaz de agir no mundo, de moldá-lo à sua imagem e semelhança, tal como o deus-homem-criador cristão; mas não apenas, também capaz de refletir seu poder de devorar, violar e expropriar: de destruir toda a criação num dilúvio, de alimentar-se de suas potencialidades criadoras, tal como Zeus que dominou o Olimpo alimentando-se de sua primeira esposa a deusa Astúcia [Métis] (Hesíodo, 2013 [séc. 8 a. c. ], p. 93).

Mas Woolf atenta para o fato que esse espelho, encarnado pela (s) mulher (es), não é qualquer espelho, é espelho mágico. Ao compreender a relação de alteridade experimentada pela (s) mulher (es) como transpassada pela metáfora do espelho mágico, isto é, ao compreender a ser-outra sendo destituída do caráter de sujeito e lançada ao polo do objeto, todavia, um objeto com poderes mágicos.

Ao mesmo tempo, a magia tem por característica o aspecto criador "caráter mesmo de ser uma força, e uma força não mecânica, mas mágica” (Mauss, 1966 [1922] p. 141). A magia se define pela capacidade de "produzir algo mais"; metamorfosear as substâncias; pelo seu polimorfismo (Mauss, 1966 [1922] p. 73). As mesmas potencialidades que Zeus rouba de Métis, ao devorá-la.

Esse poder criador das mulher (es), todavia, não mais lhes pertence; é expropriado. Ao encarnarem em exclusividade o espelho mágico, da (s) mulher (es) é retirado o caráter ativo do exteriorizar-se em outro, impelidas à pretensa passividade da "mera" re (produção), sendo concebida como repetição biológica. Desse modo, o processo de exteriorização/interiorização para a ser-mulher (es) é sobretudo estranhamento.

Há um duplo processo de exploração e opressão: expropriadas de sua condição de sujeito, a (s) mulher (es) é expurgada, por um lado, para o âmbito do trabalho doméstico (ainda que, como veremos, permaneçamos largamente exercendo funções no trabalho tido como produtivo); por outro lado, esse trabalho é, ao mesmo tempo, deposto da condição mesma de trabalho, ou seja, de exteriorização ativa, de relação entre ser consciente e natureza, de autoatividade. A mulher tornamo-nos, 
portanto, objetos de um sujeito, mas esse objeto que em sua pretensa passividade de objeto deve, contudo, magicamente conferir atividade ao sujeito ativo.

\section{CONSIDERAÇÕES FINAIS}

Concluo, assim, que temos sido destituídas da posição de partícipes da relação de reconhecimento mútuo inerente à condição de ser-humana. O caráter criador foi retirado da (s) mulher (es), sendo reduzido à pura re (produção), e perdido o sentido mesmo de trabalho. Ao mesmo tempo, as mulher (es) fomos expulsas logo, incluídas subalternamente - das atividades que passaram a concentrar o aspecto criativo e produtivo. Fomos, desse modo, destituídas da própria generidade humana ou, mais especificamente: enquanto ser-outra, nos vemos estranhadas interiorização, de modo ativo e resistente - de nós mesmas, dos objetos, de nossas filhas e filhos, das outras mulheres, e sobretudo dos homens - estes, sim, sujeitos, produtores, portadores da criação.

Entretanto,é preciso ressaltar que a experiência da alteridade enquanto estranhamento não é unívoca. A escolha pela forma "mulher (es)" vem do intuito em compreender a categoria ser-outra enquanto unidade de distintas condições e posições, ao mesmo tempo buscando apreendê-la através da escuta da pluralidade de vozes femininas. Se a ser-outra nos une, há uma infinidade de diferenças igualmente transformadas historicamente em alteridades absolutas que nos distinguem e nos separam e nos hierarquizam: mulheres negras, imigrantes, indígenas, camponesas, trans, lésbicas, queers; no mais das vezes, proletarizadas. Reforço, não obstante experimentemos a ser-mulher (es) de formas e posições distintas, ela segue nos condicionando e nos lançando ao lugar de ser-outra; como, segundo Bell Hooks já apontavam as abolicionistas negras estadunidenses no século XIX (Hooks, 1981, p. 16).

Uma ontologia marxista que não perca o movimento do real precisa ser, ao mesmo tempo, feminista, incoporando as epistemologias feministas em sua diversidade.

\section{REFERÊNCIAS BIBLIOGRÁFICAS}

A BÍBLIA. GÊNESIS (1990). Trad. Ivo Storniolo e Euclides Martins Balancin. São Paulo: Paulus.

ARRUZA, Cinzia (2016). Funcionalista, determinista e reducionista: o feminismo da reprodução social e seus críticos. Cadernos Cemarx. $\mathrm{n}^{0}$ 10. Dossie: Marxismo e feminismo no debate de gênero e sexualidade. Campinas,. 39-58.

ÁVILA, Teresa De (2011 [1577]). Castelo Interior ou Moradas. São Paulo: Paulus. 
ÁVILA, Teresa De (2019 [1562]). O Livro da Vida. São Paulo: Paulus.

BEAUVOIR, Simone (2016 [1949])O segundo sexo. Rio de Janeiro: Nova Fronteira.

BERG, Tábata (2016). Trabalho e Habitus: um diálogo entre os "jovens” Lukács e Bourdieu. Saarbrücken: Novas Edições Acadêmicas.

BUTLER, Judith (2013 [1990]). Problemas de gênero: feminismo e subversão de identidade. 6 ed. Rio de Janeiro: Civilização Brasileira.

CABNAL, Lorena (2010). In: Acercamiento a la construcción del pensamiento epistémico de las mujeres indígenas feministas comunitarias de Abya Yala. Feminismos Diversos: o feminismo comunitário. Las Segovias: ACSUR. pp. 11-25

FANON, Frantz (2006). Os condenados da terra. Juiz de Fora: UFJF.

FERGUSON (2016). Feminismo interseccional e da reprodução social: rumo a uma ontologia integrativa. Cadernos Cemarx. $\mathrm{n}^{0}$ 10. Dossie: Marxismo e feminismo no debate de gênero e sexualidadeCampinas. p. 14-38.

GONZALEZ, Lélia (1984). Racismo e sexismo na cultura brasileira. Revista Ciências Sociais Hoje, Anpocs, p. 223-244.

GONZALEZ, Lélia (1988a). A categoria político-cultural de amefricanidade. In: Tempo Brasileiro. Rio de Janeiro, No. 92/93 (jan. /jun. ), p. 69-82.

GONZALEZ, Lélia (1988b). Por um feminismo Afro-latino-americano. Caderno de Formação Política do círculo Palmarino, Vitória, v. 1, n. 1, p. 12-20. Disponível em: www. círculopalmarino. org. br. (acesso em 08/08/ 2019).

HESÍODO. TEOGONIA: A origem dos deuses (1995 [séc. 8 a. c. ]). São Paulo: Editora Iluminuras,.

HOOKS,bell 2015 [1981]. Ain'ti a woman: blackwomenandfeminism. New York e London: Routledge.

HOOKS, bell (2019 [1984]). Teoria feminista: da margem ao centro. São Paulo: Perspectiva. IRIGARAY, Luce. 1985 [1974]. Speculum of the other woman. New York: Cornell university press.

IRIGARAY, Luce (2004). Brasília: Labrys,estudos feministas.

LUKÁCS. GEORG (2003 [1922]) História e Consciência de Classe. São Paulo: Martins fontes.

LUKÁCS. GYÖRGY (2012 [1968, 1984]). Para uma ontologia do ser social I. São Paulo: Boitempo.

LUKÁCS. GYÖRGY (2013 [1968, 1984]). Para uma ontologia do ser social II. São Paulo: Boitempo.

LUXEMBURGO (1985 [1912]). Rosa. A acumulação do capital. São Paulo: Nova Cultura. MARX, Karl (2007 [1845]). “Teses ad Feuerbach”. In: A ideologia Alemã. São Paulo: Boitempo, pp. 533 - 535 . 
MAUSS, Marcel (1966 [1922]). Sociologia e Antropologia. São Paulo: Cosacnaify MBEMBE, Achille (2018). A crítica da Razão negra. 1. ed. São Paulo: N-1 Edições . MEAD. MARGARET2011 [1935]. Sexo e Temperamento. São Paulo: Perspectiva.

MIES, Maria 1998 [1996]. Patriarchy\&Accumulationon a Word Scale:women in theInternationaldivisionoflabor. New York: Zed Book,

MERLEAU-PONTY (2006 [1945]) Maurice. Fenomenologia da percepção. São Paulo: Martins Fontes.

MORISSON, Toni (2016). A origem dos outros. São Paulo: Companhia das Letras.

SCOTT, Joan (2019 [1990]). Gênero: uma categoria útil de análise histórica. Educação \& Realidade, Rio Grande do Sul, v. 20, n. 2, p. 71-99.

THOMPSON, E. P (2000 [1974]). Agenda para una historia radical Barcelona: Crítica.

WOLLSTONECRAFT, Mary (2016 [1792]). Reivindicação pelos direitos da Mulher. São Paulo: Boitempo.

WOOLF, Virginia (2016 [1928). Um teto todo seu. Rio de Janeiro: Tordesilhas.

WOOLF, Virginia (2019 [1938]). Três Guinéus. São Paulo: Autêntica,

SAFFIOTI, Heleith (2009). Ontogênese e filogênese do gênero: ordem patriarcal de gênero e a violência masculina contra mulheres. Série Estudos/Ciências Sociais/FLASCOBrasil. p. 1-44. 